\title{
O design gráfico das capas da revista Alterosa nos anos de 1939 a 1964
}

\section{Graphic design of the covers of Alterosa magazine in the years 1939 to 1964}

\author{
Yasmine Ávila Catarinozzi da Costa, Sérgio Antônio Silva, Edson Carpintero Rezende
}

Design, análise gráfica, revista, capa, Alterosa

\begin{abstract}
Este artigo propõe-se analisar a contribuição gráfica da revista Alterosa, reconhecida publicação mineira que circulou em Belo Horizonte, nos anos de 1939 a 1964. O recorte da pesquisa volta-se para as imagens e logotipos das capas, tendo como objetivo geral identificar indícios que caracterizem o design gráfico mineiro, levando em consideração o contexto histórico que estava inserida. O artigo está fundamentado na pesquisa bibliográfica e histórica, determinante para delinear o perfil da publicação, seguida da coleta de dados a partir do desenvolvimento de uma ficha/formulário. Obteve-se como resultados a identificação de características gráficas e formais das imagens, sendo a revista composta por um projeto gráfico com cores vibrantes, muitas fotografias e uso excessivo da figura feminina nas capas. Portanto, conclui-se que esta pesquisa contribui para preencher lacunas na História do Design Gráfico Brasileiro, além de servir como referência e atualização para o estudo de memória gráfica local e nacional.
\end{abstract}

Design, graphic analysis, magazine, cover, Alterosa

This article proposes to analyze the graphic contribution of Alterosa magazine, a recognized Minas Gerais publication that circulated in Belo Horizonte, in the years 1939 to 1964. The research focus is on the images and logos of the covers, with the general objective of identifying indications that characterize Minas Gerais graphic design, taking into account the historical context that was inserted. The article is based on bibliographic and historical research, which is crucial to outline the profile of the publication, followed by the collection of data from the development of a form. The results obtained were the identification of graphic and formal characteristics of the images, the magazine being composed of a graphic project with vibrant colors, many photographs and excessive use of the female figure on the covers. Therefore, it is concluded that this research contributes to fill gaps in the History of Brazilian Graphic Design, in addition to serving as a reference and update for the study of local and national graphic memory.

\section{Introdução}

Assim como o jornal, a revista tem uma história complexa moldada pelas culturas nas quais se desenvolveu. Em termos gerais, a revista é um veículo de comunicação que reúne diversos pontos de vista sobre determinado tema ou sobre vários assuntos diferentes. $\mathrm{E}$ ao contrário de outros meios, ela possui foco no leitor através de escolhas ligadas aos interesses de quem lê (SCALZO, 2016).

A chegada do século $X X$ trouxe consigo novas categorias de revistas, coloridas, populares e bem elaboradas. Com o tempo, esse tipo de publicação passou a dominar a indústria e atrair

Anais do $10^{\circ} \mathrm{CIDI}$ e $10^{\circ} \mathrm{CONGIC}$

Kelli C.A.S. Smythe, Rafael de Castro Andrade (orgs.)

Sociedade Brasileira de Design da Informação - SBDI

Curitiba | Brasil | 2021
Proceedings of the $10^{\text {th }} \mathrm{CIDI}$ and $10^{\text {th }}$ CONGIC

Kelli C.A.S. Smythe, Rafael de Castro Andrade (orgs.)

Sociedade Brasileira de Design da Informação - SBDI Curitiba | Brazil | 2021 
um vasto número de leitores. Devido à versatilidade proporcionada pelo seu suporte — o papel, as revistas permitem a interação física com o leitor, que consegue manuseá-las e aproximá-las dos olhos. Segundo Farias e Braga (2018), como documento histórico e como objeto cultural, as revistas, bem como outros impressos, podem ser entendidas como parte da cultura material de um grupo. Neste caso, é possível proceder uma análise sistemática, tanto no que diz respeito à forma gráfica, quanto à sua proposta ideológica.

Existe uma carência muito grande de estudos sobre a imprensa de Belo Horizonte. Neste caso, o artigo propõe a análise gráfica das capas da revista Alterosa, reconhecida como uma importante publicação mineira que circulou nos anos de 1939 a 1964. O objetivo é identificar indícios que caracterizem o design gráfico mineiro durante o período. Os objetivos específicos são: (i) investigar as influências do contexto histórico, do ponto de vista social, das técnicas e tecnologias de impressão; (ii) discutir sobre os resultados encontrados nesta pesquisa, os quais somam na construção da identidade e memória gráfica local.

A importância da capa vai além de proteger o miolo, visto que atua como instrumento de sedução para conquistar o público leitor, facilitando a sua identificação e engajamento em meio a outras revistas expostas nas bancas (SCALZO, 2016). Nos padrões gráficos do início do século $X X$, era comum nas capas apenas a imagem e o logotipo. As imagens nem sempre tinham relação com o conteúdo interno da publicação (MELO \& RAMOS, 2011). Já o logotipo, funciona como a representação gráfica da marca, que no caso reflete a identidade da revista.

No início do século XX, a imprensa constituiu-se em um importante instrumento de divulgação da modernização no país. O aumento do número de jornais e revistas reflete o movimento de expansão da imprensa mineira e do setor de tipografia. Nos anos 1930, a imprensa de Belo Horizonte começava a se firmar como um jornalismo mais moderno, noticioso, com linguagem mais simples e direta (PEREIRA, 2009).

O design, embora só tenha sido institucionalizado na década de $1960^{1}$, fez parte dessa reconfiguração gráfica e da vida social, contribuindo para projetar a cultura material e visual da época. Por serem atividades projetuais autenticamente brasileiras, tais produtos refletem a identidade gráfica nacional e local. Portanto, o estudo de periódicos que circularam em um dos estados mais importantes do país contribui significativamente para uma melhor compreensão de nosso legado cultural e serve como referência para o estudo da memória gráfica na academia, o aprimoramento e atualização da relevância da mesma para a sociedade.

\section{Metodologia}

O artigo está fundamentado na pesquisa bibliográfica e histórica, determinante para delinear o perfil da publicação ao longo dos anos e o contexto histórico da cidade e do campo das revistas em que esteve inserida. Foram consultados diversos artigos científicos, dissertações

\footnotetext{
${ }^{1}$ O surgimento do ensino institucionalizado de design no Brasil é datado em 1963, com a fundação da Escola Superior de Desenho Industrial no Rio de Janeiro, a ESDI/UERJ (CARDOSO, 2005).
} 
de mestrado, teses de doutorado, e livros do campo do design gráfico e do contexto histórico mineiro nas décadas de 1940 até 1960 .

A seleção do corpus analítico foi realizada a partir da consulta na plataforma digital do Arquivo Público da Cidade de Belo Horizonte ${ }^{2}$ (APCBH) e da Biblioteca Pública Estadual de Minas Gerais ${ }^{3}$. Foram selecionadas as capas que correspondem ao primeiro número publicado nos meses de agosto - mês de aniversário da revista. Os números faltantes foram substituídos pelo primeiro número dos meses de janeiro ou dezembro, totalizando 26 capas. A seguir (Figura 1), são apresentadas as fases da pesquisa. Vale ressaltar que as etapas não foram executadas de forma linear, devido ao seu caráter exploratório.

Figura 1. Fases da pesquisa. Fonte: elaborado pela autora (2021).

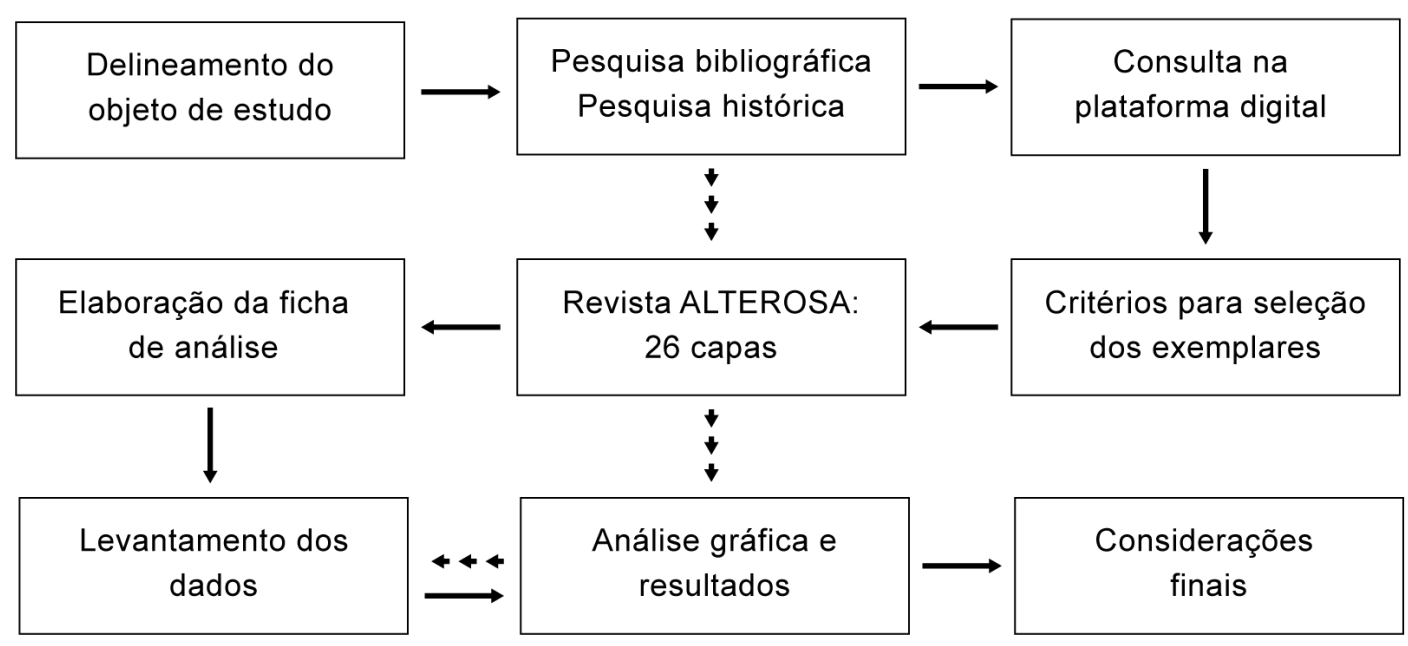

A ficha de coleta de dados para análise das imagens das capas foi adaptada a partir da proposta de Moreira e Fonseca (2018), em conjunto com os conceitos e métodos da linguagem visual de Joly (2012) (Figura 2). Para o estudo das tipografias e logotipos, optou-se por utilizar o sistema de classificação tipográfica cruzada da pesquisa de Catherine Dixon (FARIAS \& SILVA, 2004; 2005), por combinar observações a respeito de aspectos tradicionais, visuais e histórico do design de letras (Figura 3). Tais parâmetros serviram como base para desenvolver as fichas de análise conforme as necessidades do acervo em questão.

\footnotetext{
${ }^{2}$ Disponível em: https://prefeitura.pbh.gov.br/fundacao-municipal-de-cultura/arquivo-publico/acervo/revistas. Acesso em: 05 mai. 2021

${ }^{3}$ Disponível em: http://200.198.28.214/pergamum/biblioteca/index.php. Acesso em: 05 mai. 2021.
} 
Figura 2. Modelo de ficha de análise da imagem. Fonte: elaborado pela autora (2021), adaptado de Moreira e Fonseca (2018).

\section{ANÁLISE GRÁFICA DAS CAPAS DA REVISTA ALTEROSA (1939-1964)}

\begin{tabular}{|l|}
\hline IDENTIFICAÇÃO \\
\hline No da revista \\
\hline 01 \\
\hline Mês \\
\hline Agosto \\
\hline Ano \\
\hline 1933 \\
\hline Acervo 01 \\
\hline Arquivo Público da Cidade de Belo Horizonte \\
\hline
\end{tabular}

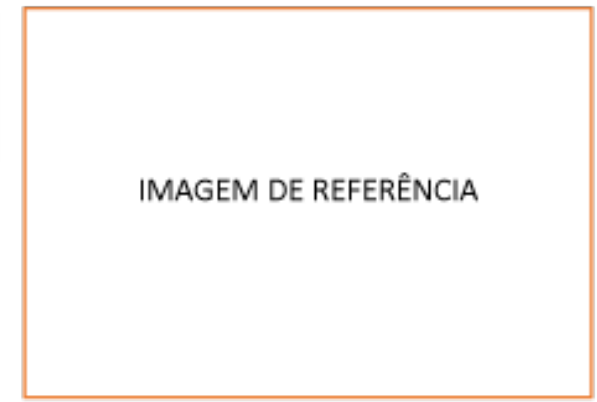

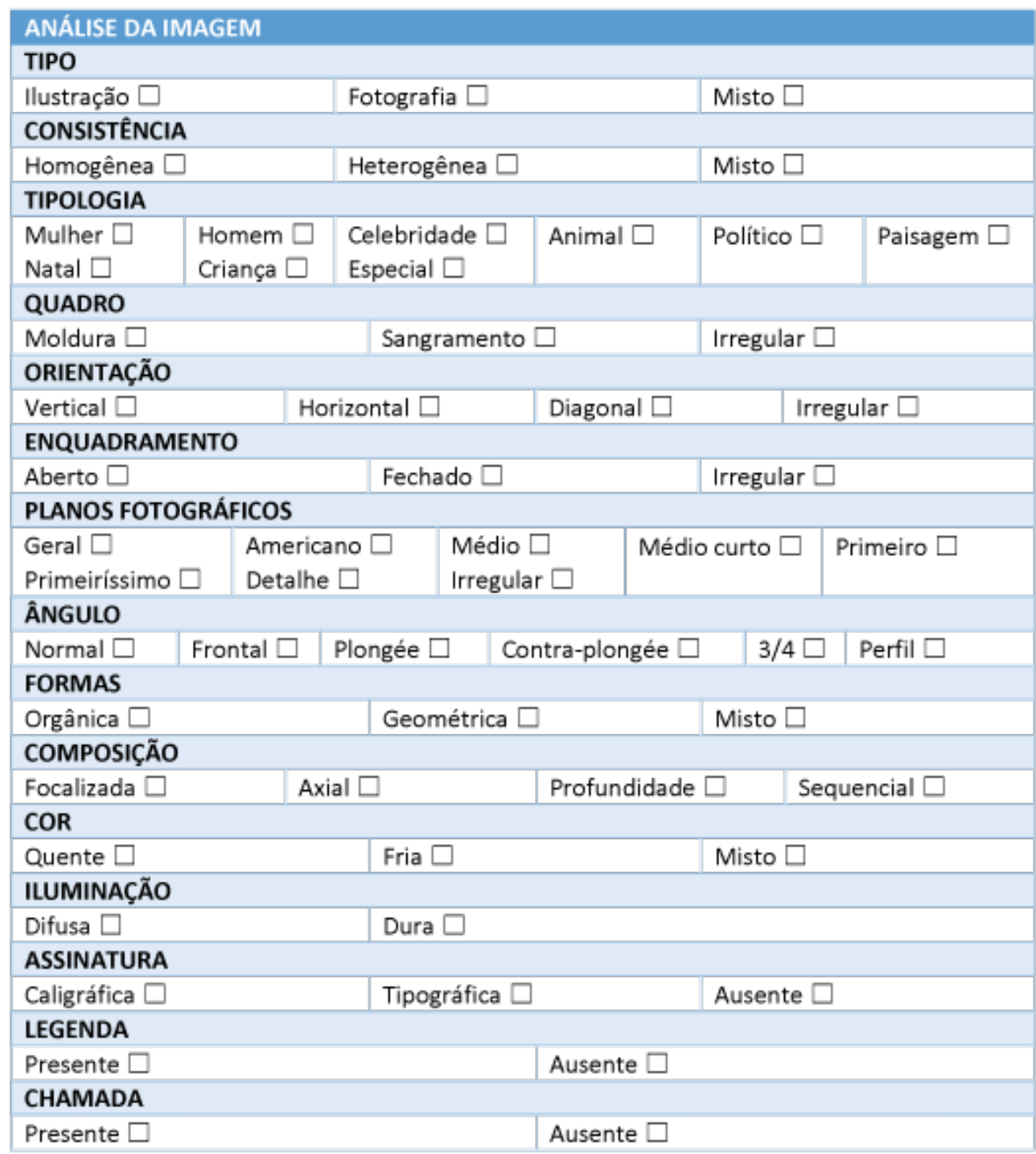


Figura 3. Modelo de ficha de análise tipográfica. Fonte: elaborado pela autora (2021).

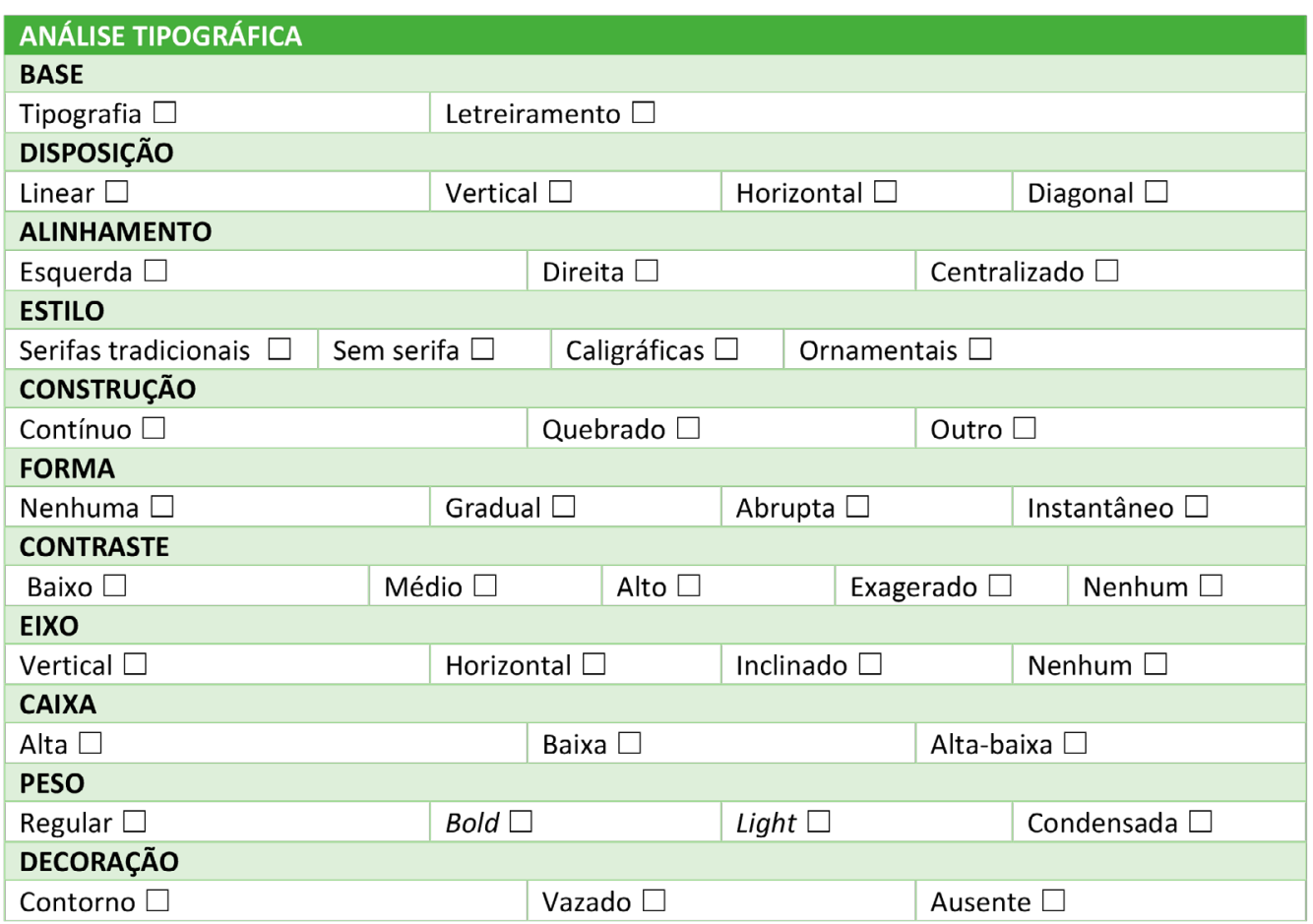

Para otimizar a coleta de dados as fichas foram desenvolvidas digitalmente através do recurso de preenchimento de formulário do Google Drive ${ }^{4}$ que gerou uma tabela automática com as respostas cadastradas. Assim, foi possível discutir sobre os resultados, no intuito de identificar as tipologias e as variáveis gráficas das capas, bem como as influências do contexto histórico que esteve inserida ao longo das edições publicadas.

\section{Análise e resultados}

A revista Alterosa foi fundada em Belo Horizonte no ano de 1939, pelo jornalista Miranda e Castro $^{5}$, e produzida mensalmente pela Sociedade Editora Alterosa Ltda., que pertencia ao mesmo jornalista. A impressão era realizada na Gráfica Queiroz Breyner Ltda., a mesma que realizava diversos trabalhos de impressão para a Sociedade Editora Alterosa Ltda. Na sua fase mais próspera chegou a ter representantes no Rio de Janeiro, São Paulo e esquema de assinatura na Europa e no continente americano.

Não encontramos na revista a explicação para a escolha do nome "Alterosa". O termo é o feminino do verbete alteroso, que segundo o Dicionário Priberam da Língua Portuguesa (2011), significa: (adj.) 1. Cheio de altivez. 2. Alto e majestoso ${ }^{6}$. De maneira informal, a expressão

\footnotetext{
${ }^{4}$ Disponível gratuitamente no site do Google.

${ }^{5}$ Olímpio de Miranda e Castro nasceu em 1914; morreu em setembro de 1962. Colaborou nas publicações Diário da Tarde, Correio Mineiro, A Montanhesa (revista de pouca duração que fundou com o dep. Fábio de Andrada). (CARVALHO \& BARBOSA, 1994).

${ }^{6}$ PRIBERAM, "alteroso", in Dicionário Priberam da Língua Portuguesa [e-book], 2011.
} 
remete a "cidade das montanhas", nome baseado na topografia local, característica do estado de Minas Gerais.

O modelo adotado era semelhante a outras revistas de variedades da época, como, por exemplo, a revista Manchete (1952/RJ), O Cruzeiro (1928/RJ), publicada pelos Diários Associados de Assis Chateaubriand (1892-1968), e em publicações internacionais como a francesa Paris Match (1949). Segundo Linhares (1995, p. 375), a qualidade gráfica, a tiragem crescente, "a reportagem fotográfica e ilustrações em profusão, todas oportunas e de muito gosto artístico" permitiram a entrada da revista Alterosa no grupo que compôs a imprensa feminina no Brasil, nos primeiros anos do século XX. Conforme o editorial, a publicação estava dentro das exigências estabelecidas da censura e registrada no Departamento de Imprensa e Propaganda $^{7}(\mathrm{DPI})$.

Naquela época, o Brasil vivenciava um processo de americanização que objetivava obter o alinhamento do país com o esforço de guerra dos EUA. Neste contexto, a revista passou por duas importantes fases. Na primeira, de 1939 a 1962, era destinada ao público mais amplo, característico dos meios de comunicação de massa. Apresentava um projeto gráfico pobre, cores opacas, ilustrações manuais. No entanto, para os padrões da época contava com uma gráfica moderna, bem como o desejo dos seus colaboradores de praticar um jornalismo profissional (MAIA \& SILVA, 2010).

Por muito tempo, os colaboradores e redatores eram pessoas famosas em Minas como o escritor Mário Matos, os poetas Djalma Andrade e João Alphonsus de Guimarães, o arquiteto Sílvio de Vasconcelos, o jornalista e compositor Vinícius de Carvalho, o ex-prefeito José Oswaldo de Araújo, a advogada Mieta Santiago, os jornalistas Hélio Vaz de Melo e Teódulo Pereira. Colaboraram também escritores nacionalmente conhecimentos como o mineiro Murilo Rubião, a paulista Maria José Dupré, a jornalista, escritora, ilustradora e correspondente internacional Olga Obry, a jornalista e contista Leonor Telles, dentre outros (MAIA \& SILVA, 2010, p. 102).

Em um tempo em que o feminismo avançava em todo o mundo, seu conteúdo editorial era destinado especialmente ao público feminino, sinalizando a mulher como representante da família. A revista fez uso constante da figura feminina nas capas, e contava com um grupo de escritoras/colaboradoras. "A mulher mineira da capital passa a ser exibida como um ícone e símbolo de modernidade para as mulheres do interior do estado e do restante do país" (REIS \& TAVARES, 2015, p. 6). A partir de 1953, a publicação passou a ser publicada quinzenalmente. Nos anos de 1960, entrou em crise de vendas e voltou à circular mensalmente.

Em 1962, Miranda e Castro vende o periódico ao político Magalhães Pinto ${ }^{8}$, então governador de Minas Gerais, desencadeando ampla reforma editorial comandada por Roberto

\footnotetext{
${ }^{7}$ Criado em 1939, já sob o regime do Estado Novo, era um órgão de controle e censura, além de um importante difusor da propaganda e divulgação dos feitos e propostas do governo para o país e sua população. Avaliada a inexequibilidade dos objetivos para os quais havia sido criado, e diante da crescente pressão popular, foi extinto em 25 de maio de 1945 (LUCA, 2011).

${ }^{8}$ José de Magalhães Pinto, natural de Santo Antônio do Monte, Minas Gerais, nasceu em 28 de junho de 1909 e faleceu em 3 de março de 1996. Advogado, economista, banqueiro e político brasileiro com atuação em Minas Gerais, estado do qual foi governador e representou no Congresso Nacional
} 
Drummond $^{9}$ (REIS \& TAVARES, 2015). Nesta segunda fase, adotou um tom mais político, com a redução dos assuntos cotidianos e típicos das revistas femininas. As reportagens sobre a política nacional e internacional ganharam destaque ocupando quase toda a página.

Posteriormente, a publicação foi vendida à Editora Abril, maior responsável pelo segmento de revistas no país, que adquiriu as máquinas da Sociedade Editora Alterosa Ltda. e optou, em 1964, por encerrar a revista mineira (MARTINI, 2017).

No total de 26 capas analisadas, foram encontradas 25 imagens que usam fotografias e apenas uma capa com ilustração. Isso se deve ao fato de que "as fotografias, nesse período, eram fruto da modernização dos aparatos tecnológicos utilizados pela imprensa e eram também consideradas um fator de distinção entre os periódicos" (MARTINI, 2017, p. 34). Ao classificar as imagens de acordo com suas tipologias, nota-se que todas as capas, inclusive a ilustração, possuem a temática relacionada à figura feminina. As primeiras capas traziam senhorinhas da sociedade brasileira, especialmente de Minas Gerais. A partir do pós-guerra temos a presença constante de personalidades hollywoodianas, como Barbara Stanwyck, Loretta Young, Lizabeth Scott, Abbe Lane, entre outras (Figura 4). O sorriso, expressão recorrente nas capas, é visto "como índice de felicidade, em conjunto com o artifício da iluminação da face da estrela, tinha enorme apelo no imaginário social", e consequentemente na construção da identidade feminina (BARROS, 2017, p. 195). Foram encontradas outras tipologias menos recorrentes, como animais, Natal e edição comemorativa de aniversário. Algumas imagens poderiam ter ocorrência de mais de uma tipologia em simultâneo.

Figura 4. Capa com mulher da sociedade tradicional mineira, Srta. Lúcia Valares (N. 1 - Ago/1939); 2) Capa com personalidade hollywoodiana, atriz Lizabeth Scott (N. 88 - Ago/1947); 3) Capa com ilustração (N. 361 - Jan/1963). Fonte: Arquivo Público da Cidade de Belo Horizonte (APCBH) e Biblioteca Pública Estadual de Minas Gerais.
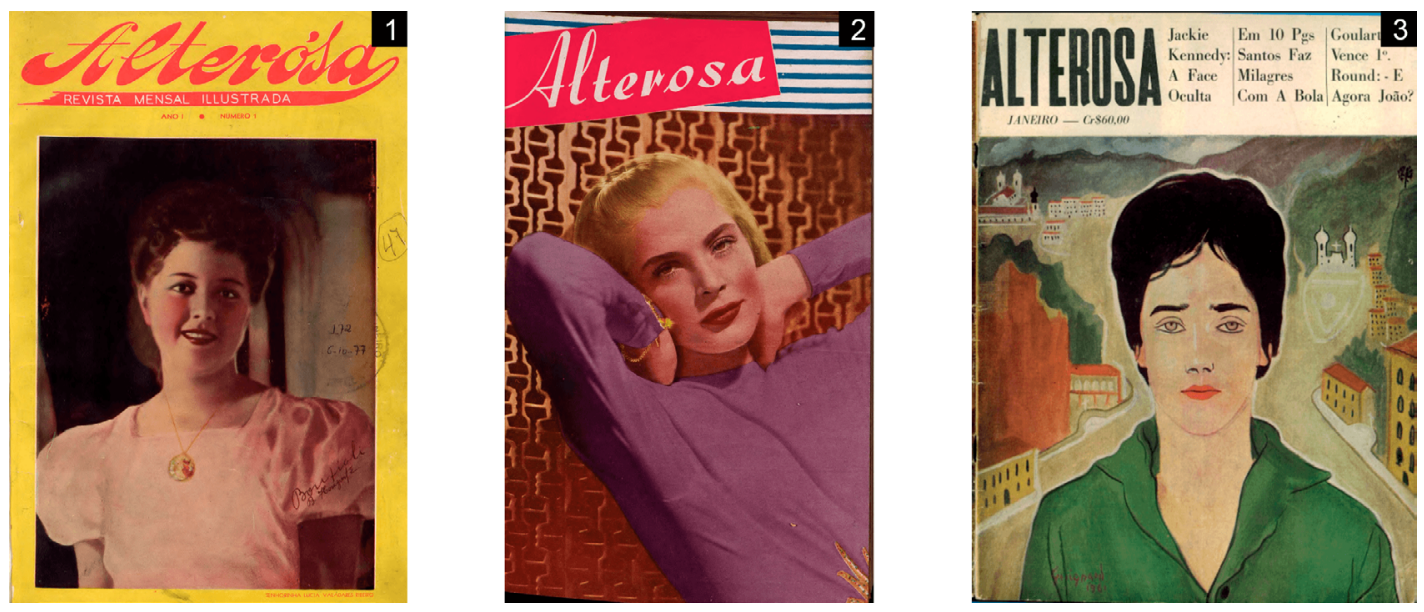

\footnotetext{
${ }^{9}$ Roberto Francis Drummond, nascido em Santana dos Ferros, Minas Gerais, em 21 de dezembro de 1933 e faleceu em 21 de junho de 2002, em Belo Horizonte. Romancista, jornalista e cronista brasileiro, iniciou sua incursão pela literatura ainda bem jovem, escrevendo contos e radionovelas com apenas 13 anos. Suas principais obras são: Ontem à Noite Era Sexta-feira, Sangue de Coca-Cola, A Morte de D.J em Paris e Hilda Furacão (CARVALHO; BARBOSA, 1994).
} 
O contraste entre as massas de cores e as formas orgânicas da figura humana, que, são arredondadas e suaves, dão a impressão de delicadeza e feminilidade. Em relação à consistência da imagem, apenas cinco capas possuíam mais de uma técnica, as quais misturavam as técnicas de ilustração e fotografia numa mesma imagem. Considerando a época, essa deficiência em relação às experimentações de técnicas e materiais pode ter acontecido devido ao alto custo de produção dos clichês ${ }^{10}$ de impressão no Brasil (BENTO \& FONSECA, 2019). A Alterosa, que era impressa em tipografia, passou a não ser competitiva, quando comparada as revistas que já trabalhavam no sistema offset. Era preciso fazer um clichê específico para tipografia, gerando um peso muito alto no valor da publicidade (PEREIRA, 2009).

Na percepção das cores e da luz, a interpretação é antropológica e cultural, e ambas têm um efeito psicofisiológico sobre o espectador (JOLY, 2012), visto que percebidas podem se assemelhar a experiências anteriores e reativar sensações ou impressões de prazer, saudosismo, alegria, tristeza, entre outras. A maior parte das capas foram impressas em tricromia ou policromia, termo utilizado para designar o processo de impressão que utiliza três ou quatro cores. Isto se deve ao aprimoramento técnico durante os séculos, como a criação do primeiro processo de impressão de fotografias coloridas e a invenção do filme fotográfico, que permitiram que as fotografias apresentassem melhor qualidade, e consequentemente, as cores se tornaram mais frequentes. Em relação à temperatura, nota-se o uso de cores frias, como azul, verde e violeta, transmitindo ao leitor uma sensação de frieza, mas também de tranquilidade, assim como de cores quentes, vermelho, amarelo e laranja para causar um efeito ou sentimento de calor, alegria e dinamismo. Esses esquemas de cores geram um contraste na página, que se destaca entre as demais na banca chamando a atenção do leitor.

A maior parte das imagens encontra-se na posição vertical. Essa disposição dos elementos foi natural devido ao formato da revista. As imagens possuem o enquadramento fechado, sendo um indicativo de proximidade. Para causar esse efeito, são utilizados especialmente o plano médio, feito da cabeça até a cintura, o médio curto, uma variante do plano anterior que apanha o corpo desde a cabeça até meio do peito, e o primeiro plano, tendo como elemento central o rosto e os ombros, o qual serve para mostrar confiança e intimidade. Os ângulos mais recorrentes são o normal, quando a câmera está no nível dos olhos, dando a impressão de objetividade e estabilidade, seguido do 3/4, em que a câmera forma um ângulo de 45 graus com o nariz da pessoa (Figura 5).

\footnotetext{
${ }^{10}$ Matrizes de metal com imagem e/ou texto em relevo que podem ser produzidos através da estereotipia, galvanotipia ou fotogravura (PORTA, 1958).
} 
Figura 5. 1) Primeiro plano, ângulo $3 / 4$ (N. 100 - Ago/1948); 2) Plano médio curto, ângulo normal (N. 167 - Ago/1953); 3) Plano médio, ângulo normal (N. 239 - Ago/1956). Fonte: Arquivo Público da Cidade de Belo Horizonte (APCBH) e Biblioteca Pública Estadual de Minas Gerais.
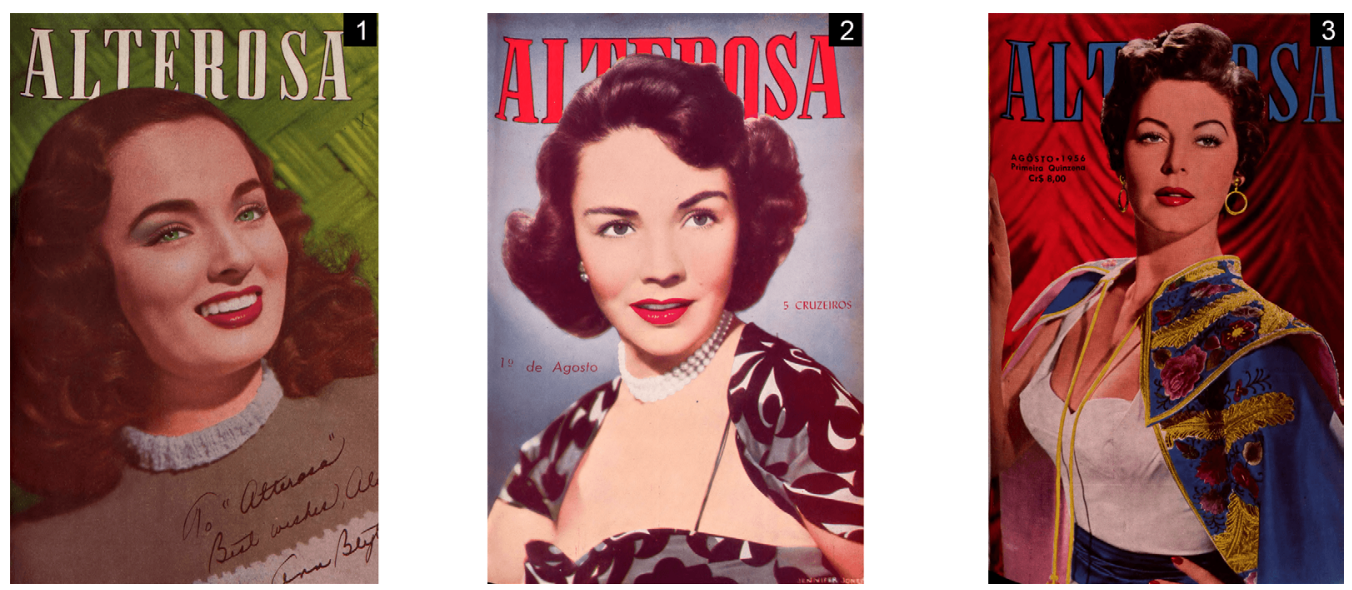

As capas apresentam uma composição equilibrada, com a fotografia geralmente

centralizada e em primeiro plano, indicando um trabalho de construção axial, quando a imagem é posta no eixo do olhar, e de profundidade, sugerindo um cenário em perspectiva (Figura 6). A fotografia não é circunscrita por uma moldura e aparece cortada, isto é, coincide com os limites do suporte. Essa técnica sugere a ideia de amplidão (MEGGS; PURVIS, 2009), e provoca o leitor a construir em seu imaginário o que não se vê no campo visual da representação, o fora de campo. Esse procedimento remete implicitamente ao universo cinematográfico. Por outro lado, a capa de N. 11 (Dez/1940) possui a composição assimétrica em eixo vertical. Aqui, tal efeito encerra parte da representação visual e aproxima-se da tradição pictórica (JOLY, 2012). O logotipo muitas vezes era colocado segundo plano, sempre na parte superior. A distribuição dos elementos no campo visual denota um certo domínio, por parte dos artistas gráficos, de critérios básicos da composição visual, como hierarquia, equilíbrio e contraste. 
Figura 6. 1) Composição assimétrica (N. 11 - Dez/1940); 2) Construção em profundidade (N. 263 Ago/1957); 3) Construção axial (N. 287 - Ago/1958). Fonte: Arquivo Público da Cidade de Belo Horizonte (APCBH) e Biblioteca Pública Estadual de Minas Gerais.
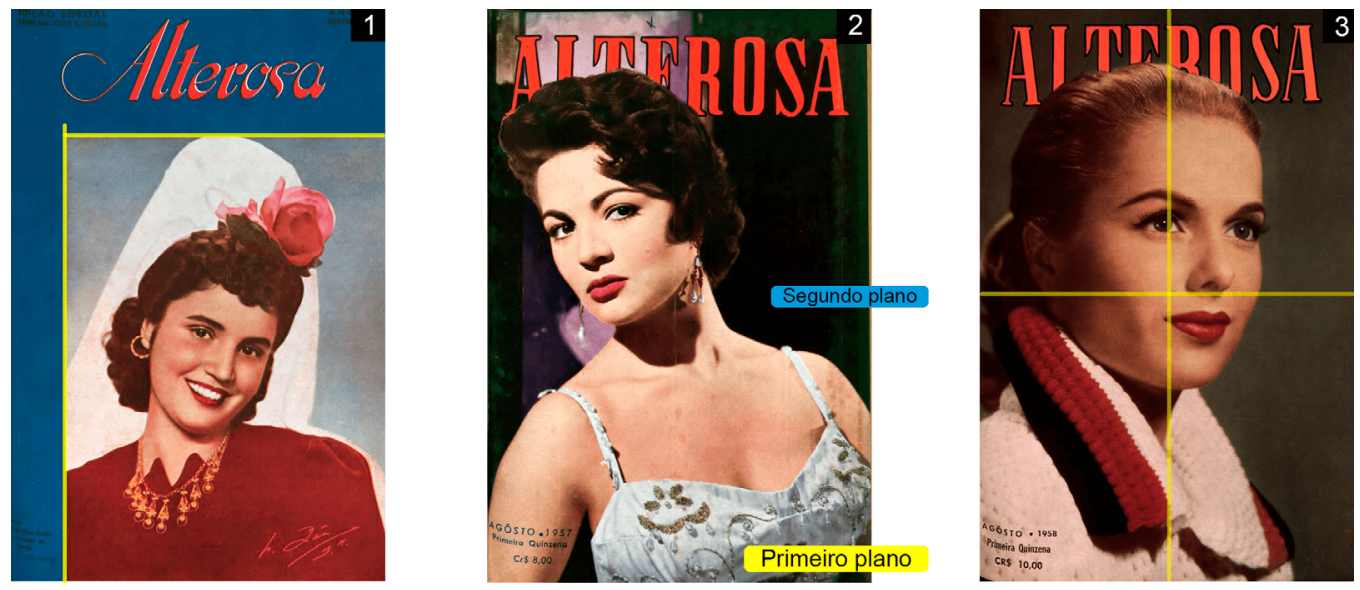

Ao analisar a presença ou não das assinaturas dos autores, pôde-se observar que cerca de $70 \%$ das imagens não possuem autoria. Os poucos que assinavam seu nome, o faziam de forma caligráfica e em menor número de forma tipográfica. Já em relação ao uso de legendas, foram encontradas em apenas cinco capas, geralmente nas que traziam senhorinhas da sociedade brasileira (Figura 7). A ausência de assinatura nas imagens das capas levanta lacunas em relação à trajetória das técnicas de fotografia utilizadas e quem foram os profissionais e ilustradores recorrentes ao longo dos seus 25 anos de circulação. A partir da década de 1960, as chamadas nas capas tornam-se mais frequentes com títulos que referenciam matérias jornalísticas e temas sobre moda, cinema, saúde e política.

Figura 7. 1) Capa com assinatura caligráfica (N. 17 - Ago/1941); 2) Capa com legenda e assinatura tipográfica (N. 40 - Ago/1943); 3) Capa com chamada (S/N - 1964). Fonte: Arquivo Público da Cidade de Belo Horizonte (APCBH) e Biblioteca Pública Estadual de Minas Gerais.
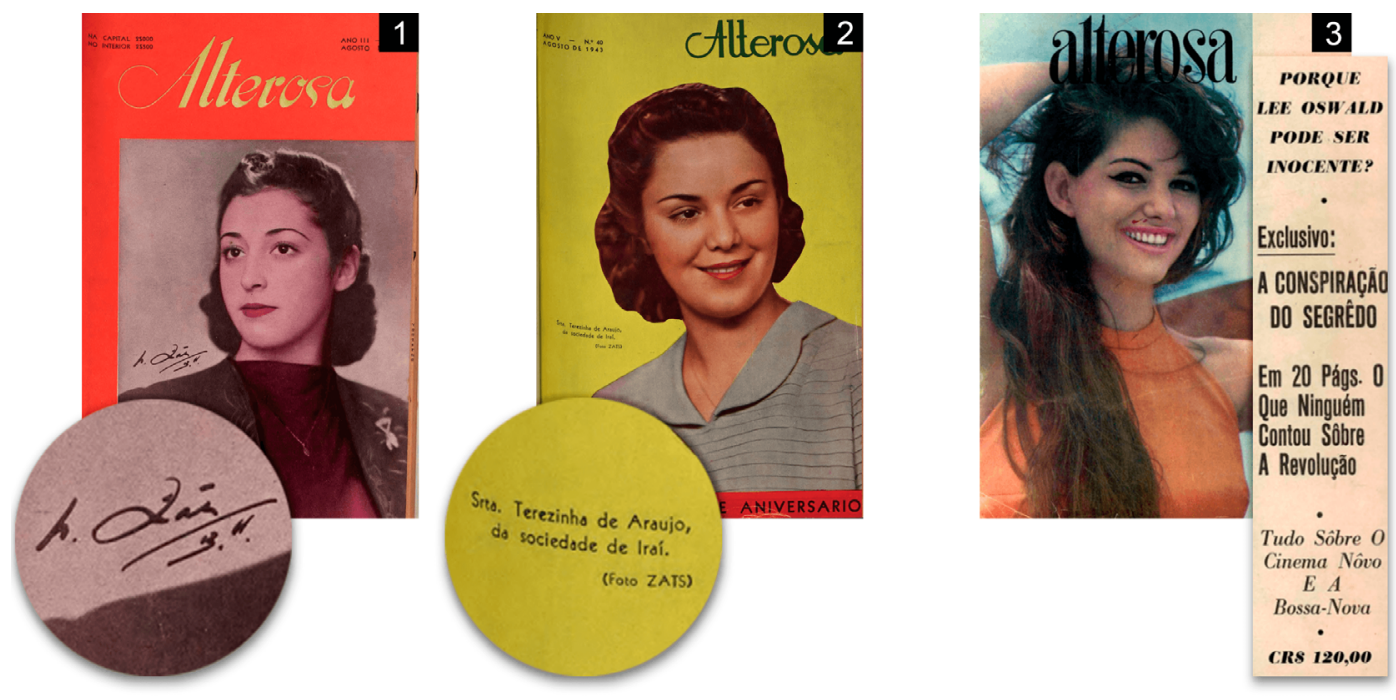


\section{Logotipos}

O logotipo geralmente aparece em segundo plano, alinhado à esquerda em seis capas; centralizado em dezenove; e à direita em uma. A partir de 1948 a 1958, nota-se que a parte superior da imagem sobrepõe parte do logotipo. Apenas nos últimos anos o logotipo passou sobrepor a imagem. Predomina a disposição horizontal linear; e apenas uma em diagonal. As letras com peso regular e eixo vertical estão presentes em vinte e um logotipos. Em cinco casos o eixo é inclinado, e em quatro o peso é condensado. O tipo em caixa alta está presente em vinte e cinco exemplares, em oito deles ocorre uma associação entre caixa alta e baixa; e apenas um é formado exclusivamente de caixa baixa. Muitas vezes o clichê com o mesmo logotipo era utilizado repetidas vezes e variava apenas o uso da cor escolhida para cada capa. A seguir serão apresentados os logotipos mais recorrentes durante o período analisado e comentadas suas principais características.

Os primeiros logotipos a remetem a tipografia caligráfica (ou cursiva), com eixo e contraste variáveis. Elas se aproximam da escrita humana, possuem formas mais orgânicas e aparência de manuscrito produzido com pena caligráfica ou pincel, e passam maior sensação de humanização, cada qual com sua variação de estilo (Figura 8). Destaque para a edição N. 40 (Ago/1943), que possui o desenho tipográfico geométrico, com serifas arredondadas e aspecto circular, o que sugere influências modernistas.

Figura 8. Exemplos de logotipo com padrão caligráfico caixa alta-baixa (respectivamente, N. 1 - Ago/1939; N. 28 - Ago/1942; N. 40 - Ago/1943; N. 88 - Ago/1947. Fonte: Arquivo Público da Cidade de Belo Horizonte (APCBH) e Biblioteca Pública Estadual de Minas Gerais.
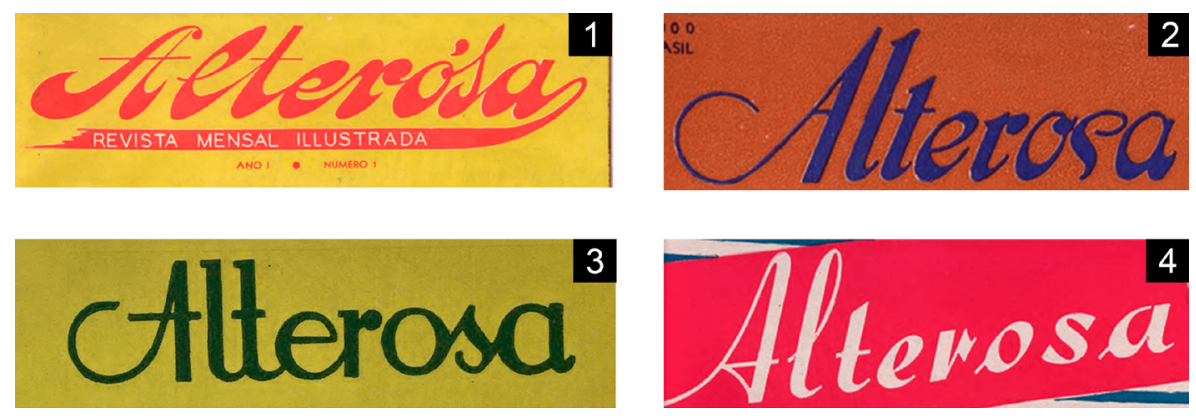

Quatorze capas exibem logotipos que remetem as classes referentes às serifas tradicionais, subdivididas em humanistas, garaldinas, transicionais, didônicas e serifas quadradas (SILVA \& FARIAS, 2005). Tendem a ser geométricas, com a barra do 'e' horizontal, o eixo vertical e o contraste extremo. Os logotipos das edições N. 100 (Ago/1948) e N. 319 (Dez/1959) apresentam a perna do caractere ' $R$ ' afastada da junção entre o bojo e haste, característico do estilo art déco. Observa-se ainda que edição sem número de 1964, possui o desenho tipográfico próximo da fonte Bodoni, com terminais circulares em que a forma remete à de um círculo (Figura 9). 
Figura 9. Exemplos de logotipos que remetem as classes de serifas tradicionais em caixa alta e, depois, caixa baixa (respectivamente, N. 64 - Ago/1945; N. 100 - Ago/1948; N. 319 - Dez/1959; S/N - 1964. Fonte: Arquivo Público da Cidade de Belo Horizonte (APCBH) e Biblioteca Pública Estadual de Minas Gerais.
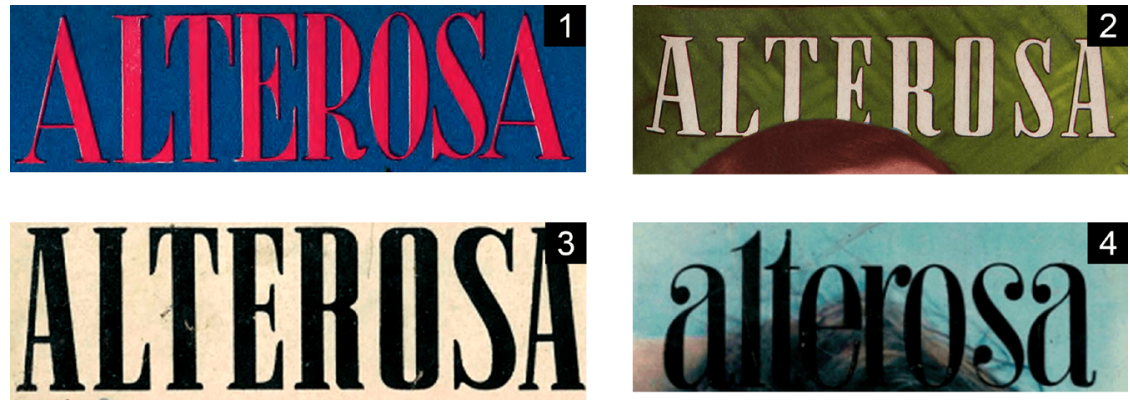

Entre os anos 1950 e 1960, os logotipos abandonaram gradativamente os tipos serifados e passaram a usar sans serif. Seu design limpo e simples as tornas ideais para títulos. Os tipos sem serifas da edição N. 360 (Dez/1962), são baseados em formas geométricas, e possuem o contraste nulo, a construção contínua e o eixo vertical. A barra posicionada na metade inferior do 'A' reflete influências do estilo art déco (Figura 10). De modo geral, considerando todos esses aspectos pode-se afirmar que esses desenhos tipográficos embora não sejam um art déco e/ou art nouveau puro sofreram influências modernistas.

Figura 10. Exemplo de logotipo com padrão sem serifa caixa alta (N. 360 - Dez/1962). Fonte: Arquivo Público da Cidade de Belo Horizonte (APCBH).

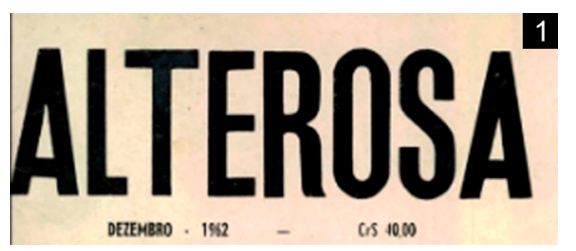

\section{Considerações finais}

O artigo apresenta os resultados obtidos através de análise gráfica realizada nas imagens e logotipos das capas da revista Alterosa nos anos de 1939 a 1964. De modo geral a aplicação do método foi efetiva, mas demonstrou-se complexa devido à abrangência de variáveis gráficas, podendo comprometer em certa medida a confiabilidade dos resultados encontrados. Ainda assim, foi possível reforçar a utilização de métodos de análise da imagem e de classificações tipográficas, bem como contribuir com a reconstituição do passado e da história do design gráfico local e nacional.

Diante dos resultados encontrados, percebe-se que a revista explorou as tecnologias disponíveis da época e com as novidades que surgiam, principalmente por meio da fotografia colorida. Ocorreram alterações gráficas significativas nas capas, indicando novas tendências e maior consistência de edição, como faixas coloridas, maior padronização dos títulos e "chamadas" ou anúncios de matérias que o leitor encontraria no interior da revista. Os desenhos tipográficos passaram por mudanças, de um padrão caligráfico, com suas variações, 
para um padrão tipográfico serifado caixa alta e, depois, caixa baixa. Essa passagem de letras cursivas no estilo "assinatura" para fortes tipos sem serifa trouxe mais força e impacto. Nesta época era comum o logotipo fazer parte da imagem, consequentemente, existia uma variedade muito grande de clichês tipográficos.

A publicação acompanhou o processo de modernização que alterou a dinâmica social da cidade, por afirmar hábitos e reconfigurar o comportamento de homens e mulheres de Belo Horizonte. Na busca por maior ou menor aceitação do público consumidor os padrões assumidos pela revista se modificaram ao longo dos anos. No entanto, manteve a figura feminina como foco de suas capas, não perdendo a sua identidade inicial, e possibilitando compreender a representação de padrões sociais, que mescla a mulher do lar brasileiro, figuras idealizadas, donas de casa, mães dedicadas e amorosas com a mulher moderna, sensual e sofisticada do cinema norte-americano/estadunidense e europeu.

Por fim, as capas da revista Alterosa recriam uma identidade gráfica e editorial marcada por representações sociais, em que a divisão entre o período de primeira fase apresenta o retrato de uma sociedade, inicialmente mineira - local, expandindo para o contexto nacional e internacional, que, estava alinhado à cultura de massa norte-americana e ao projeto nacionalista do presidente Getúlio Vargas, conhecido por Estado Novo (1937-1945).

\section{Agradecimento}

O presente trabalho foi realizado com apoio da Coordenação de Aperfeiçoamento de Pessoal de Nível Superior Brasil (CAPES).

\section{Referências}

Alterosa: a revista da família brasileira. Belo Horizonte: Sociedade Editora Alterosa,1939-1964. Mensal.

Barros, Gelka A. (2017). Bela e sadia! A mulher nas páginas da revista Alterosa (1939-1945) durante o Estado Novo e o processo de americanização do Brasil. Comunicação e Sociedade, v. 32, p. 191-210.

Bento, Amanda A., \& Fonseca, Letícia P. (2019). Análise das imagens das capas da revista Vida Capichaba. Anais do $9^{\circ}$ Congresso Internacional de Design da Informação (CIDI). Belo Horizonte.

Cardoso, Rafael (Org.). (2005). O design brasileiro antes do design: aspectos da história gráfica, 1870 - 1960. São Paulo: Cosac Naify.

Carvalho, André \& Barbosa, Waldemar. (1994). Dicionário Biográfico: Imprensa Mineira. Belo Horizonte: Armazém de Ideias.

Farias, Priscila. L., \& Braga, Marcos da C. (Org.). (2018). Dez ensaios sobre memória gráfica. São Paulo: Blucher. 
Farias, Priscila L., \& Silva, Fabio L. C. M. (2004). Classificações tipográficas: sistemas de classificação cruzada. Anais do P\&D Design $/ 6^{\circ}$ Congresso Brasileiro de Pesquisa e Desenvolvimento em Design. FAAP: São Paulo.

Joly, Martine. (2012). Introdução à análise da imagem. Campinas, SP: Papirus.

Linhares, Joaquim N. (1995). Itinerário da imprensa de Belo Horizonte 1895-1954. Belo Horizonte: Fundação João Pinheiro.

Luca, Tânia R. de. (2011). A produção do Departamento de Imprensa e Propaganda (DIP) em acervos norte-americanos: estudo de caso. Revista Brasileira de História. São Paulo, v. 31 , $n^{\circ} 61$, p. 271-296.

Maia, Cláudia J., \& Silva, Telma. B. da. (2010). Alterosa para a Família do Brasil: breve história de um periódico. Caminhos da História, v. 15, p. 97-112.

Martini, Cristiane O. P. (2017). Regule-se, exercite-se, embeleze-se: pedagogias para o corpo feminino pelo discurso da revista Alterosa (1939-1964). Tese (Doutorado em Educação) Faculdade de Educação, Universidade Federal de Minas Gerais, Belo Horizonte.

Meggs, Philip.; Purvis, Alston W. (2009). História do design gráfico. Trad. Cid Knipel. São Paulo: Cosac Naify.

Melo, Francisco I. S. H. de, \& Coimbra, Elaine. R. (2011). Linha do tempo do design gráfico no Brasil. São Paulo: Cosac Naify.

Moreira, Luiza A., \& Fonseca, Letícia P. (2018). Proposta de ficha de coleta de dados para análise de acervos de imagens. São Paulo: Blucher, p. 1208-1224.

Pereira, Lígia M. L. 200 anos da indústria gráfica no Brasil: trajetória em Minas Gerais. Belo Horizonte: Prefácio Comunicação, 2009.

Porta, Frederico. (1958). Dicionário de artes gráficas. Rio de Janeiro: Editora Globo.

Reis, Letícia J., \& Tavares, Frederico. (2015). Revista Alterosa pré e pós-venda: vestígios de uma construção identitária (1959-1964). XX Congresso de Ciências da Comunicação na Região Sudeste. Minas Gerais.

Silva, Fábio. L. C. M., \& Farias, Priscila. (2005). Um panorama das classificações tipográficas. Estudos em Design, v. 11, n. 2, p. 67-81.

Scalzo, Marília. (2016). Jornalismo de revista. 4. ed. São Paulo: Contexto.

\section{Sobre o(a/s) autor(a/es)}

Yasmine Ávila Catarinozzi da Costa, Mestranda em Design, UEMG, Brasil

<yasmineavilac@outlook.com>

Sérgio Antônio Silva, Dr., UEMG, Brasil <sas.sergiosilva@gmail.com>

Edson Carpintero Rezende, Dr., UEMG, Brasil <edson.carpintero@gmail.com> 